\title{
Selection of compositions for additive technologies in construction
}

\author{
Anastasiia Sharanova ${ }^{*}$ and Maria Dmitrieva \\ Immanuel Kant Baltic Federal University, 14 Nevskogo St, Kaliningrad 236016, Russia
}

\begin{abstract}
Three-dimensional printing is an innovative digital technology and is one of the most significant achievements in the industrial and technological development of modernity. Digital 3D technologies have reached a colossal level of development over a period of about half a century since their invention. Using 3D printing in the construction of lowrise buildings, it becomes possible to implement almost any ideas and achieve the best architectural expressiveness of objects. The aim of this work is to create cement-based compounds that can be used in additive construction methods. A review of the scientific literature on this topic was carried out, the main components of the mixture were identified, and a series of field experiments were conducted. According to the results of the work, the optimal composition for 3D construction printing was determined.
\end{abstract}

\section{Introduction}

Additive technology in the industry today is quite common. However, the construction industry is very conservative and lags behind other industries in terms of using 3D printing. The lack of a regulatory framework, the need for the development of building materials for 3D printing and the high cost of equipment are the main problems, the solution of which will ensure the rapid development of additive construction technologies. Despite the fact that large world institutes and large corporations are engaged in research and development of additive construction technologies, there is a great potential for scientific research in this area.

Today, additive construction technologies are attracting more and more investment. Interest in the use of $3 \mathrm{D}$ printing in the construction industry is mainly the result of the expectation of unlimited design of forms, elements and structures, at the same time providing new aesthetic and functional features [1]. The growth of interest in additive technologies is due to many factors: a high level of production automation, improved product quality, accelerated construction processes, the ability to optimize CAD models, a decrease in production waste. These factors contribute to the enormous interest in using additive technologies in construction and using 3D prototyping instead of traditional construction methods. The commercial success of $3 \mathrm{D}$ printing is to create a reliable design

\footnotetext{
* Corresponding author: a.sharanova@gmail.com
} 
and manufacturing process, the ability of architects and engineers to develop certified materials and building elements. [2].

The basis of the work of a 3D printer is the principle of gradual (layered) creation of a solid model that is "grown" from a certain material. As known, the main difference between a 3D printer and any other industrial robot lies in the way of product creation. In particular, a 3D construction printer has a nozzle or an extruder and squeezes the rapidhardening working mixture out of it. The surface on which the volumetric product is created (the working zone) has dimensions specified by the nozzle stroke. In this case, the construction of formwork is not required. That is, the construction machine of volumetric printing is declared as a self-sufficient mechanism capable of creating a finished building from scratch.

Another way to build with a 3D printer is to create individual elements by extrusion and build the finished elements directly on the construction site. In the work [1], the authors want to emphasize that the manufacture of individual structural elements using 3D printing can introduce a new rational use of AM (Additive Manufacturing) technologies in design, because it allows the manufacture of complex shapes, reduces the amount of concrete used, eliminates complex formwork systems, and simplifies transportation and installation.

Building material for the construction of supporting structural elements (walls, floors) is a rapid-hardening reaction-powder concrete, reinforced with steel or polymer microfiber. The peculiarity of the reaction-powder concrete is the absence of coarse aggregate without loss in the ratio of binders/solid component, as well as the highest performance characteristics. Cheaper types of concrete can also be used, such as fine-grained and sand concrete modified with additives (hyperplasticizers, hardening accelerators, fiber). The advantage of the technology lies in the speed of construction - the machine can build an individual residential house of $150 \mathrm{~m}^{2}$ in 24 hours [3].

In order to develop a dry construction mix for a 3D construction printer, it is necessary to determine the requirements that must be placed on such concrete, both at the mix stage and in the hardened state. The main task of developing a composition for printing is to give the material sufficient flow for free extrusion through the extruder nozzle, and at the same time sufficient viscosity to preserve the printed form. For this purpose, the composition must have thixotropy, i.e. have a high yield strength at rest and low viscosity during extrusion. [2,4,5,]. Extrudability, shape retention, buildability and thixotropic opening time are defined as critical properties of the early age of concrete for 3D printing [6]. In terms of providing traditional requirements, known methods and approaches should be applied in the technology of concrete, mortars and dry construction mixtures. Various mineral additives, industrial and building waste can also be used. To ensure special requirements for the composition, due to the peculiarities of the technology, besides the use of traditional approaches in concrete science, new non-standard formulation and technological solutions will be required to facilitate the practical implementation of 3D printing technology in construction.

Currently, the development of various technologies of 3D construction printing is mainly happening abroad, but in Russia the development of additive technologies in construction is gaining momentum. Russia's first 3D printing house was built in Stupino, Moscow Region. This house was printed on a mobile industrial 3D-printer by Apis Cor. The construction of the house took place on the territory of the Stupino factory, which became a test site for the Apis Cor experiment. 


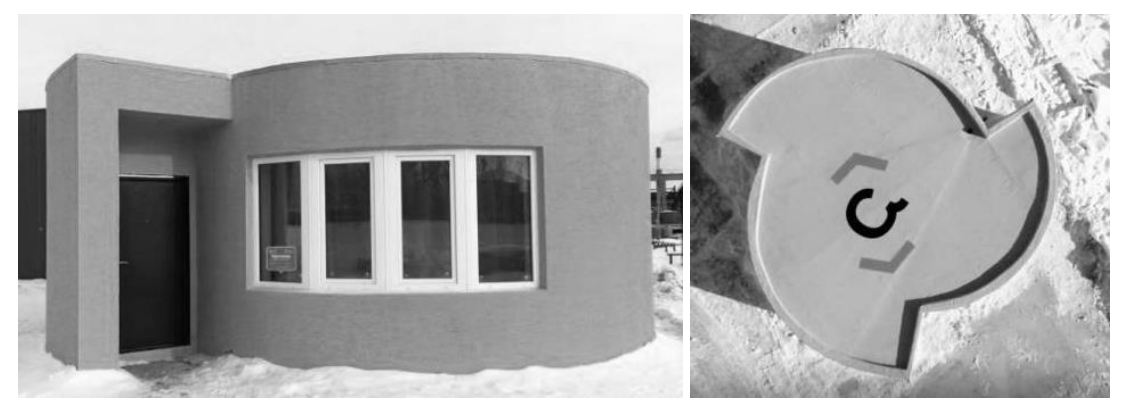

Fig. 1. Apis Cor 3D printed house [7]

Printing of bearing structures took a little less than 24 hours. Construction was carried out in the winter using concrete mix, which cannot be used when the temperature drops below five degrees Celsius. The 3D printer itself can work up to minus 35 degrees. In the end, the problem was solved with a canopy, which helped to keep the optimal temperature. This moment is very important, because in Russia there are northern regions in which the construction of new buildings is really big problems and they are partly related to temperature. The developer also notes that with the advent of new materials, such as geoconcrete, it will be possible to do without canopies. The house is able to withstand temperatures up to minus 60 degrees Celsius, has a high level of sound insulation and a service life of up to half a century [7].

In Yaroslavl, Russia, the company SPECAVIA in 2015 built a one-story cottage with an attic. A specific feature of construction in Russia is the mandatory calculation of the frost resistance of materials, as well as temperature fluctuations. The cottage was built in the pavilion of a large cottage size in order to avoid precipitation on the frame of the future building. For equipment of SPECAVIA, there are 15 different compositions of dry building mixtures. One of the companies producing such compounds is 3D EFT HAND. SPECAVIA works with such materials as modified waterproof gypsum with the addition of diatamite beads, gypsum with glass and polyester fibers, kaolin mixtures [8]. In October 2017, SPETSAVIA presented the first residential building in Europe printed on a 3D printer. The developers claim that the building fully complies with all the rules and regulations of individual housing construction.

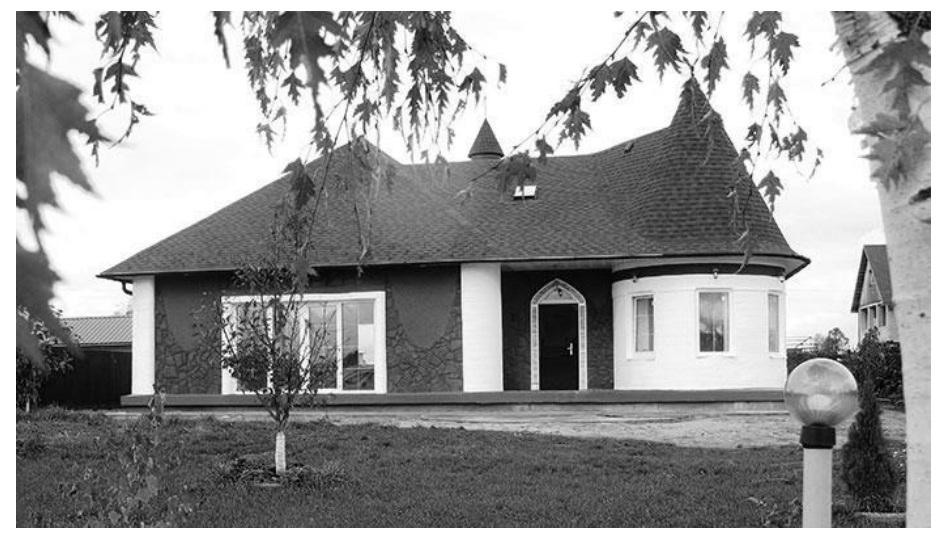

Fig. 2. Residential house printed by SPECAVIA company [8]

The building was printed on a serial printer of the portal type with dimensions of $3.5 \times 3.6 \times 1 \mathrm{~m}$, as a material - sand concrete M-300. Printing was carried out in layers with a 
height of $10 \mathrm{~mm}$ and a width of 30 to $50 \mathrm{~mm}$ at a speed of printing walls up to $10 \mathrm{~m}^{2} /$ hour, the building area is $298.5 \mathrm{~m}^{2}$.

\section{Literature review}

Every year the number of articles on additive technologies in scientific journals is becoming more and more. This confirms the fact that the development of 3D-printing goes to the leading places in all areas of science and industry. In construction, researchers mainly study compositions for three-dimensional printing, their properties and characteristics. As in ordinary concrete, they are based on a binder (cement, fly ash, silica fume, kaolin clay, etc.). In ordinary concrete, sand, crushed stone or gravel are used as aggregates. In concrete for $3 \mathrm{D}$ printing, due to the small diameter of the extruder nozzle, only sand of various fractions is used, as well as reinforcement with glass or polypropylene fiber and a small amount of water for setting. An integral part is chemical additives that give concrete the properties required for printing (plasticizers, accelerators or curing retarders, waterreducing additives, etc.).

T.T.Le et al. [9] introduce concepts to determine the workability of the concrete mix used in $3 \mathrm{~d}$ printing (extrudability, workability, open time, buildability). According to the results of practical experiments, the optimum composition that meets printing requirements was determined: the ratio of sand to binder ( $70 \%$ cement, $20 \%$ fly ash, $10 \%$ silica fume) 3: 2, water-cement ratio -0.26 . Reinforcement - polypropylene fiber in the amount of $1.2 \mathrm{~kg} / \mathrm{m}^{3}$ of the binder mass, additives - superplasticizer and retarder $(1 \%$ and $0.5 \%$ of the binder mass, respectively). This mixture provides the flowability of the concrete mix for 100 minutes, which allows the researchers to print a wall with a height of 61 layers through a nozzle with a diameter of $9 \mathrm{~mm}$ without any special damage to the bottom layer. Compressive strength after 28 days is $110 \mathrm{MPa}$.

In the scientific works of S.C.Paul et al. [10] and B. Panda et al. [11] reflects the main theses, description of the research and its results, regarding the use of $3 \mathrm{D}$ printing in construction and processes that affect the strength characteristics of the obtained samples. The main topic of research is the strength of the final printed product when using geopolymer solution. Results are considered when changing various printing parameters, such as: speed, direction, nozzle size, and so on. Studies are based on the fact that when using different basic components and methods for determining strength, as well as under different environmental conditions, the strength characteristics will differ.

To achieve all the advantages of concrete printing capable of creating complex shapes, it is necessary to study the strength properties of the samples, as well as to conduct in-depth studies to improve the structural, mechanical and durable properties. One of the main goal of $3 \mathrm{D}$ concrete printing is the correct selection of the composition, because in the absence of formwork, the concrete mix must meet special rheological properties. The mixture should not only be loaded and pumped out of the extruder, but also support the weight of the subsequent layers, keeping its shape. And one of the promising research is the study of a huge range of various additives, using which it will be possible to control these processes. Printer settings also play an important role. In the study [10], a printed geopolymer was obtained by adding thixotropic additives to a traditional geopolymer solution. A small amount of water was added to the mixture to make it printable. The rheometer was used to test the geopolymer for flowability and viscosity. In order to investigate the effect of printing parameters, the printed samples were tested for tensile and compressive strength. According to the results, from the point of view of rheology, it was observed that the yield strength and viscosity of the geopolymer mixtire increase with time due to the polycondensation reaction. Sample density also increased, possibly due to pressure during the extrusion process. According to research results, it turned out that the direction of 
loading of the printed sample affects the strength properties. This underlines the importance of choosing the right direction for 3D concrete printing [11]. Many scientists have also investigated the speed of printing as a decisive factor in printing. The balance between the printing speed and the board width of the printed layer can satisfy the necessary strength properties. Higher speed provides a smaller side width. It was also investigated that greater strength provides a smaller distance between the layer and the nozzle. [10]. Studies of single-layer extruded material have shown that the mechanical strength of extruded samples may be higher than for cast samples. The mechanism for gaining high strength was due to the formation of a dense solution during the extrusion process. All parameters, both printing and the material itself have a huge impact on the strength of the printed sample. And only rational use, as well as intensive research of all aspects, can ensure the use of all the advantages of $3 \mathrm{D}$ concrete printing.

Another group of researchers (A. Perrot, D. Rangeard, A. Pierre [12]) is studying the mechanical strength of a printing mixture consisting of cement, kaolin clay and lime filler with a water-cement ratio of 0.41 and polycarboxylate powder as an additive. A sample column of fresh mixed concrete with a diameter of $70 \mathrm{~mm}$ was subjected to a load on a press that simulates the load created by the upper printed layers. Thus, the researchers determined the optimal printing speed, based on a comparison of the vertical stress acting on the first deposited layer, with the critical stress associated with the plastic deformation of the material. A. Kazemian et al. [13] also use a cylindrical test to determine the tensile strength of the lower fresh printed layers of the concrete mix. Experimental data showed that the inclusion of silica fume and nano-clay (highly purified attapulgite clay) increases the stability of the form of a fresh printed mixture. In addition, a slight increase in strength is observed as a result of the addition of polypropylene fiber.

It is also important that construction using additive technologies is less harmful to the environment than traditional methods. This also applies to the used materials. B. Panda et al. [14] suggest using geopolymer concrete as a printed composition, the main components of which are industrial waste. As a binder in geopolymer concrete, fly ash and slag, which are waste products of the metallurgical industry and heat and power engineering, are used. The use of these materials reduces the cost of construction, their reserves in the world are enormous, since humanity is only embarking on the path of recycling and its use in various fields. The strength characteristics of geopolymer concrete are no worse than usual, and in some cases even exceed all expectations [14]. In work [4], 10 compositions of geopolymer concrete with various contents of industrial wastes, such as fly ash, slag and silica fume, are examined. It is noted that the addition of microsilica significantly affects the fresh properties of the printing mixture, in particular viscosity, while the addition of slag provokes the development of early strength geopolymer composition. The yield strength, viscosity and thixotropy were determined, which are considered as key properties for the successful implementation of 3D printing processes.

In [5], an additive based on nano clay is used besides microsilica. The authors note that the addition of a small amount of nano clay and microsilica increases the buildability by $150 \%$ and $117 \%$, respectively, and significantly increases the thixotropy and initial strength of the samples (green strength - up to 60 minutes after mixing). The positive effect of the addition of nano clay and microsilica has been proven by calorimetric analysis - compounds containing additives show a greater heat release during the hydration process, which leads to an increase in the initial strength.

Particular attention is paid to the characteristics of the fresh mix for printing, namely the mechanical behavior of the material in the printing process. In [15], the authors investigate the properties of the mixture from 0 to 90 minutes after the formation of the layer, since it is this period of time that is particularly important for successful concrete printing. The fresh printed mixture must retain its shape under the weight of the layers printed above. For the 
study, the authors developed a numerical model of the mechanical behavior of an early age of concrete for printing from 0 to 90 minutes. Subsequently, the model was tested by comparing with printed experiments. The numerical model is considered suitable for analyzing the structural behavior of concrete during 3D printing and the qualitative prediction of the corresponding fracture-strain mode. In this study, it was found that the Young's modulus, compressive strength and shear strength are a linear function of time and develop in proportion to the age of fresh concrete.

The rheological properties of a concrete mix, such as ultimate shear stress, viscosity and relaxation period, also play a very important role. In [9], it was determined that the shear stress of a concrete mix suitable for printing should be in the range of $0.3-0.9 \mathrm{kPa}$. With a value of $<0.3 \mathrm{kPa}$, the mixture is too liquid, and with a value of $>0.9$ - too hard to extrude. In [16], the authors developed a high-thixotropy concrete composition for 3D printing. The rheological characteristics of the material (viscosity, yield stress, thixotropy) and the strength of the printed specimens were determined depending on the direction of load application. The developed composition has high flowability before printing, which prevents nozzle clogging, and keeps its shape well after printing. The result of the development of this material is a full-size printed bus stop.

B. Panda et al. [17] study the anisotropic properties of the printed composition with the addition of glass fibers of different lengths and dosages. The results showed that increasing the fiber content up to $1 \%$ improves the strength characteristics of the material in all extrusion directions (perpendicular, parallel and along the printed layers).

\section{Materials and methods}

According to the results of a modern scientific research review in the field of additive technologies in construction, seven main compositions of cement-based mixtures were identified for this research.

Materials:

- Portland cement Eurocem super 500, CEM I 42.5H, Petersburg Cement;

- Fine-grained sand, fraction $0.315 \mathrm{~mm}+$ sieve residue $0.16 \mathrm{~mm}$; origin location:

Kaliningrad region;

- Fly ash, Poland;

- Microsilica fume (MS), Poland;

- Highly active metakaolin (MTK): white, country of origin: Russia, Chelyabinsk region, Synergo;

- Slaked lime: Wapno, Poland;

- Polypropylene fiber: length of $12 \mathrm{~mm}$, thickness of $35 \mu \mathrm{m}$, country of origin: Russia;

- Stachemalt RS: complex additive (plasticizer and set retarder), Stachema, Poland;

- Stachement 1267: hyperplasticizer based on polycarboxylates, Stachema, Poland.

Consumption of materials is shown in Table 1.

Table 1. Materials per $1 \mathrm{~m}^{3}$ of concrete mixture

\begin{tabular}{|c|c|c|c|c|c|c|}
\hline $\begin{array}{l}\text { No. } \\
\text { sampl. }\end{array}$ & W/C & $\begin{array}{c}\text { Cement, } \\
\mathrm{kg} / \mathrm{m}^{3}\end{array}$ & $\begin{array}{l}\text { Sand, } \\
\mathrm{kg} / \mathrm{m}^{3}\end{array}$ & $\begin{array}{c}\text { Water, } \\
1 / \mathrm{m}^{3}\end{array}$ & $\begin{array}{c}\text { Fly ash, } \\
\mathbf{k g} / \mathrm{m}^{3}\end{array}$ & $\begin{array}{c}\mathrm{MS}, \\
\mathrm{kg} / \mathrm{m}^{3}\end{array}$ \\
\hline 1 & 0.52 & 545.3 & 1168 & 402 & 234 & - \\
\hline 2 & 0.45 & 545.3 & 1168 & 350 & 234 & - \\
\hline 3 & 0.45 & 545.3 & 1168 & 350 & 234 & - \\
\hline 4 & 0.46 & 545.3 & 1168 & 360 & 234 & - \\
\hline 5 & 0.46 & 545.3 & 1168 & 360 & 156 & - \\
\hline 6 & 0.67 & 390.0 & 1168 & 520 & - & - \\
\hline 7 & 0.84 & 545.3 & 1168 & 460 & - & 156 \\
\hline
\end{tabular}




\begin{tabular}{|c|c|c|c|c|c|}
\hline \multirow{2}{*}{$\begin{array}{c}\text { No. } \\
\text { sampl. }\end{array}$} & \multirow{2}{*}{$\begin{array}{l}\text { MTK, } \\
\mathrm{kg} / \mathrm{m}^{3}\end{array}$} & \multirow{2}{*}{$\begin{array}{l}\text { Lime, } \\
\mathrm{kg} / \mathrm{m}^{3}\end{array}$} & \multicolumn{3}{|c|}{ Additives } \\
\hline & & & Fiber, $\mathrm{kg} / \mathrm{m}^{3}$ & St.RS, $1 / \mathrm{m}^{3}$ & St.1267, $1 / \mathrm{m}^{3}$ \\
\hline 1 & - & - & 1.2 & 8 & - \\
\hline 2 & - & - & 1.2 & - & - \\
\hline 3 & - & - & 1.2 & 8 & - \\
\hline 4 & - & - & 1.2 & - & 8 \\
\hline 5 & 78 & - & 1.2 & - & 11.7 \\
\hline 6 & 195 & 195 & 1.2 & - & 11.7 \\
\hline 7 & 78 & - & 1.2 & - & 11.7 \\
\hline
\end{tabular}

For each composition were identified:

- Setting time by the Vicat apparatus with a needle (Russian State Standard GOST 30744-2001 [18]);

- Normal consistency by the Vicat apparatus with a plunger (GOST 30744-2001 [18]);

- Flowability using ring spreading (using a ring test by the diameter of the mixture spread flowing out of the ring when the ring is removed, GOST 31356-2007 [19]);

- Consistency of fresh concrete by dipping steel cone (GOST 5802-86 [20]);

- Compressive and flexural strength of samples at the age of 28 days (GOST 30744$2001[18])$.

\section{Results and discussion}

Table 2 shows the results of the tests.

Table 2. Results

\begin{tabular}{|c|c|c|c|c|c|c|}
\hline \multirow[b]{2}{*}{$\begin{array}{l}\text { No. } \\
\text { sampl. }\end{array}$} & \multirow[b]{2}{*}{$\begin{array}{l}\text { Density, } \\
\mathrm{kg} / \mathrm{m}^{3}\end{array}$} & \multicolumn{2}{|c|}{ Setting time } & \multirow{2}{*}{\multicolumn{2}{|c|}{$\begin{array}{c}\text { Normal } \\
\text { consistency (h } \\
\text { from the plate), } \\
\text { mm }\end{array}$}} & \multirow[b]{2}{*}{$\begin{array}{l}\text { Flowability by } \\
\text { ring test, } \mathrm{cm}\end{array}$} \\
\hline & & Initial, $\mathbf{h}$ & Final, $\mathbf{h}$ & & & \\
\hline 1 & 1974.1 & 5 & 6 & & 2 & 8 \\
\hline 2 & 2117.4 & $4 \mathrm{~h} 30 \mathrm{~min}$ & 6 & & 40 & 6.4 \\
\hline 3 & 1984.1 & 4 & $6 \mathrm{~h} 30 \mathrm{~min}$ & & 40 & 6.6 \\
\hline 4 & 1984.9 & 3 & 4 & & 25 & 6.4 \\
\hline 5 & 2050.1 & 4 & 5 & & 9 & 6.75 \\
\hline 6 & 1957.9 & 3 & $3 \mathrm{~h} 40 \mathrm{~min}$ & & 2 & 6.75 \\
\hline 7 & 1967.3 & $2 \mathrm{~h} 30 \mathrm{~min}$ & $3 \mathrm{~h} 50 \mathrm{~min}$ & & 40 & 7.05 \\
\hline \multirow{2}{*}{$\begin{array}{l}\text { No. } \\
\text { sampl. }\end{array}$} & \multirow{2}{*}{\multicolumn{2}{|c|}{$\begin{array}{l}\text { Consistency by dipping } \\
\text { steel cone, } \mathrm{mm}\end{array}$}} & \multicolumn{4}{|c|}{28 days strength, MPa } \\
\hline & & & \multicolumn{2}{|c|}{ Compressive } & \multicolumn{2}{|r|}{ Flexural } \\
\hline 1 & \multicolumn{2}{|c|}{8.65} & \multicolumn{2}{|c|}{40.8} & \multicolumn{2}{|r|}{4.9} \\
\hline 2 & \multicolumn{2}{|c|}{3.05} & \multicolumn{2}{|c|}{49.0} & \multicolumn{2}{|r|}{7.5} \\
\hline 3 & \multicolumn{2}{|c|}{3.25} & \multirow{2}{*}{\multicolumn{2}{|c|}{$\begin{array}{l}41.5 \\
33.0\end{array}$}} & \multicolumn{2}{|r|}{6.0} \\
\hline 4 & \multicolumn{2}{|c|}{3.15} & & & \multicolumn{2}{|r|}{6.2} \\
\hline 5 & \multicolumn{2}{|c|}{6.125} & \multicolumn{2}{|c|}{52.0} & \multicolumn{2}{|r|}{7.8} \\
\hline 6 & \multicolumn{2}{|c|}{5.3} & \multicolumn{2}{|c|}{29.4} & \multirow{2}{*}{\multicolumn{2}{|c|}{$\begin{array}{l}4.6 \\
4.7 \\
\end{array}$}} \\
\hline 7 & & 83 & \multicolumn{2}{|c|}{39.2} & & \\
\hline
\end{tabular}

In this study, we investigated 7 potential compositions suitable for additive methods in construction. Samples No. 2 and No. 3 turned out to be too thick, which is unacceptable for extrusion, but showed sufficient strength for 28 days. Sample No. 1 turned out to be too liquid and flow, i.e. during extrusion will not hold the form, setting time is also unacceptable for use in 3D printing. Samples No. 6 and No. 7 showed the fastest setting 
time, but the samples of these compositions at the age of 28 days did not gain the sufficient strength. The early setting in composition No. 7 is caused by the presence of microsilica, which contributes to a faster start of the hydration reaction, but does not affect the increase in the final strength of the material. Sample No. 4 has an early hardening time and good density, but at the same time it has insufficient strength. Sample No. 5 showed the highest compressive strength and flexural strength at the age of 28 days, the mixture turned out to be quite flow and relatively thick for extrusion, setting time was also within the normal range. According to the test results, it can be concluded that composition No. 5 is suitable for use in construction using $3 \mathrm{D}$ printer.

\section{Conclusions}

The aim of the work was to determine the optimal composition of concrete for 3D printing in construction. An analytical review of modern scientific research in the field of additive technologies in construction was conducted. According to the results of the analytical review, seven main compositions of cement-based mixtures were identified for further research. It was found that the composition containing cement, fly ash and metakaolin in certain proportions (No. 5) is most suitable for use in 3D construction printers. This composition is quite mobile and relatively thick for extrusion and has a sufficient curing rate. Concrete samples of composition No. 5 showed the highest compressive strength and flexural strength at the age of 28 days.

The obtained results make it possible to further study the compositions with the best characteristics, their application directly for experimental construction using the method of additive technologies. It becomes possible to create such research directions in Russia as the study of materials for construction 3D printing, in particular the development of dry building mixtures for the additive technologies in the construction industry. The lack of regulatory documents, state standards and technical conditions in this area slows down the process of bringing 3D printing construction to mass use. Therefore, it is necessary to carry out as much research in this area as possible and give support to research teams that work on promising additive technologies in construction.

\section{References}

1. D. Asprone, F. Auricchio, C. Menna, V. Mercuri, Constr. Build. Mater. J. 165, 218-231 (2018)

2. R.A. Buswell, W.R. Leal de Silva, S.Z. Jones, J. Dirrenberger, Cem. Concr. Res. J. 112, 37-49 (2018)

3. A.O. Torshin, E.N. Potapova, Adv. Chem. Chem. Techn. J. 7 (176), 118-120 (2016) (rus)

4. B. Panda, C. Unluer, M.J. Tan, Cem. Concr. Compos. J. 94, 307-314 (2018)

5. Y. Zhang, Yu. Zhang, G. Liu, Y. Yang, M. Wu, B. Pang, Constr. Build. Mater. J. 174, 263-271 (2018)

6. B. Panda, M.J. Tan, Ceram. Int. J. 44 (9), 10258-10265 (2018)

7. Apis Cor. Available at: apis-cor.com. (accessed: 15.10.2018). (rus)

8. Specavia. Available at: ww.specavia.pro. (accessed: 15.10.2018) (rus)

9. T.T. Le, S.A. Austin, S. Lim, R.A. Buswell, A.G.F. Gibb, T.Thorpe, Mater. Struct. J. 45. 1-12 (2012)

10. S.C. Paul, Y.W.D. Tay, B. Panda, M.J. Tan, Arch. Civ. Mech. Eng. J. 18 (1), 311-319 (2018)

11. B. Panda, P.Suvash, M.J. Tan, Mater. Lett. J. 209, 146-149 (2017) 
12. A. Perrot, D. Rangeard, A. Pierre, Mater. Struct. J. 49, 1213-1220 (2016)

13. A. Kazemian, X. Yuan, E. Cochran, B. Khoshnevis, Constr. Build. Mater. J. 145, 639647 (2017)

14. B. Panda, S.C. Paul, L.J. Hui, Y.W.D. Tay, M.J. Tan, J. Clean. Prod. 167, 281-288 (2017)

15. R.J.M. Wolfs, F.P. Bos, T.A.M. Salet, Cem. Concr. Res. J, 106, 103-116 (2018)

16. Y. Zhang, Yu. Zhang, W. She, L. Yang, G. Liu, Y. Yang, Constr. Build. Mater. J. 201, 278-285 (2019)

17. B. Panda, S.C. Paul, M.J. Tan, Mater. Lett. J. 209, 146-149 (2017)

18. State Standard 30744-2001. Cements. Methods of testing with using polyfraction standard sand (Standartinform Publ., Moscow, 2001) (rus)

19. State Standard 31356-2007. Dry building cement binder mixes. Test methods (Standartinform Publ., Moscow, 2007) (rus)

20. State Standard 5802-86. Mortars. Test methods (Standartinform Publ., Moscow, 1986) (rus) 